\title{
A multi-user virtual environment to support students' self-efficacy and interest in science: A latent growth model analysis
}

\section{Citation}

Chen, Jason A., M. Shane Tutwiler, Shari J. Metcalf, Amy Kamarainen, Tina Grotzer, and Chris Dede. 2016. "A Multi-User Virtual Environment to Support Students' Self-Efficacy and Interest in Science: A Latent Growth Model Analysis." Learning and Instruction 41 (February): 11-22. doi:10.1016/j.learninstruc.2015.09.007.

\section{Published Version}

doi:10.1016/j.learninstruc.2015.09.007

\section{Permanent link}

http://nrs.harvard.edu/urn-3:HUL.InstRepos:37231286

\section{Terms of Use}

This article was downloaded from Harvard University's DASH repository, and is made available under the terms and conditions applicable to Open Access Policy Articles, as set forth at http:// nrs.harvard.edu/urn-3:HUL.InstRepos:dash.current.terms-of-use\#OAP

\section{Share Your Story}

The Harvard community has made this article openly available.

Please share how this access benefits you. Submit a story.

Accessibility 


\section{A Multi-User Virtual Environment to Support Students' Self-Efficacy and Interest in Science: A Latent Growth Model Analysis}

Using latent growth models, we explored: (a) The effect of middle school students' (n=189) preintervention science self-efficacy and science interest on their initial interest in an Ecosystems Multi-User Virtual Environment (EcoMUVE) and the rate of change in their interest in EcoMUVE; and (b) the mediating effect of students' initial interest in EcoMUVE and rate of change in interest on students' post-intervention science self-efficacy and interest in science. Results showed that: (1) students' pre-intervention self-efficacy for science had an effect both on students' triggered situational interest for EcoMUVE and on students' maintained situational interest for EcoMUVE; (2) both triggering and maintaining situational interest in EcoMUVE were important in developing students' science self-efficacy. In fact, maintained situational interest was the stronger predictor; and (3) maintained situational interest for EcoMUVE translated into individual interest for the science content. Results support and extend social cognitive theory as well as models of interest development.

Keywords: Technology, self-efficacy, interest, science education, latent growth model

\section{Rationale}

Although immersive technologies like games and simulations have the potential to serve as a "hook" for students' interest in academic activities, some research has shown that the effects of participating in the technology activity on students' academic interests are often short-lived because the novelty of the technology wears out quickly (Clark, 1983; Deaney, Ruthven, \& Hennessy, 2003; Moos \& Marroquin, 2010), or that students' interests in the technology activity do not transfer to students' interests in the academic subject (Torff \& Tirotta, 2010). Other studies have also shown that technology-rich activities, especially highly immersive ones, can even distract students from the salient academic content, thereby interfering with students' motivation and learning (Adams, Mayer, MacNamara, Koenig, \& Wainess, 2012; Moreno \& Mayer, 2004).

Despite these findings that technology-rich activities can often thwart meaningful learning and motivation, Multi-User Virtual Environments (MUVE) that simulate the types of scientific reasoning that actual scientists enact can potentially support and bolster students' 
motivation in science (cf., Barab, Gresalfi, \& Ingram-Goble, 2010; Chen, Metcalf, \& Tutwiler, 2014; Ketelhut, 2007). We base this premise on theories of motivation that outline the necessary conditions that develop students' competence beliefs (i.e., "Can I succeed in this activity?") and their value beliefs (i.e., "Is this activity enjoyable or useful to me?"). These conditions include providing (a) opportunities to successfully accomplish increasingly more complicated tasks; (b) meaningful choices of goals for students to pursue; and (c) opportunities to work collaboratively with others. Furthermore, past studies with an Ecosystems MUVE (EcoMUVE) have shown that, although students were initially drawn to the novelty of the technology, and that the novelty did wear off over time (Authors, 2013), students' interest development in science over the course of the intervention differed based on the degree to which they identified with science (Authors, 2014). Therefore, technology-rich environments that allow students to use salient scientific knowledge and skills to enact the types of scientific reasoning skills that scientists enact may be an effective way to create situational interest (SI) with the technology activity, which Hidi and Renninger (2006) defined as "focused attention and the affective reaction that is triggered in the moment by environmental stimuli, which may or may not last over time" (p. 113). We posit that this SI for the technology activity, which in our case is generated by immersing students in a collaborative game-like task that simulates in a fun way how scientists think through complex problems, can foster the development of students' more enduring individual interests, which Hidi and Renninger defined as “a person's relatively enduring predisposition to reengage particular content over time" (p. 113). This has been an ongoing challenge for designers and educators - to create engaging technology-rich activities that allow students to transfer their excitement for the technology-based activity into an enduring interest in science. 
Our overall goal was to extend the literature concerning the development of situational interest into individual interest within text-based tasks to more complex scenarios involving technology-rich contexts that simulate the type of intellectual reasoning that scientists perform in real life. Given that the majority of research exploring the development of interest has been done in text-based tasks, there is a great need to move beyond these tasks to more complex, naturalistic, classroom-based tasks, especially those involving technology-rich activities. There is reason to believe that the motivational dynamics between interest and self-efficacy are different for learning environments such as EcoMUVE compared to reading texts. For example, tasks within programs like EcoMUVE are quite complicated-often done in collaboration with others, and involving many self-directed tasks in which students have to recruit a large variety of cognitive resources to solve complex problems. The stimuli that are present to both trigger and maintain SI within such learning environments like EcoMUVE can potentially be much more diverse and intense than those presented in text-based tasks.

Another goal was to explore "profiles" of triggered and maintained SI for a technologyrich activity that relate to the development of students' individual interests in a subject. These profiles were formed using latent growth analysis, which modeled the combination of students' initial interest in EcoMUVE (i.e., triggered SI in EcoMUVE) and their rate of change in EcoMUVE interest (i.e., maintained SI in EcoMUVE). This "interest profile" was modeled as a mediator of students' pre-intervention science self-efficacy and interest on their post-intervention self-efficacy and interest. By modeling SI in this way, we were able to explore the interest profiles that do and do not translate SI for a technology-based activity into individual interest for a subject - a problem that has plagued instructional design for years. We next situate this phenomenon in the interest development literature. 


\section{Theoretical Framework}

\subsection{Interest and its Development}

Although technology-rich activities are often seen as a key component in motivating and engaging today's $21^{\text {st }}$ Century learners, there are legitimate critiques of this generalization (Chen, Zap, \& Dede, 2012; Dede, 2009; Moos \& Marroquin, 2010). Immersive technology-based activities are often criticized as being capable of only generating interests for novel aspects of the technology itself rather than in a subject area-eliciting a novelty effect (Clark, 1983; Moos \& Marroquin, 2010). Once the novelty of the technology wears off, students' interests in both the technology and the subject likely diminish. However, recent research has indicated pedagogical elements of technology-rich activities employing strong design and pedagogy can overcome technology's novelty effect (see Dalgarno \& Lee, 2010). In fact, we posit that technology-rich activities that allow students sufficient autonomy to explore a problem, provide virtual tools allowing students to gain competence in collecting and analyzing information, and couch the process of scientific inquiry in a meaningful and fun context can facilitate the development of students' interests with technology-based activities into more enduring interests with a subject. We hypothesize that, although a novelty effect for the technology may be exhibited, there may be a corresponding increase in students' interest in science.

Hidi and Renninger's (2006) four-phase model of interest development outlines how students develop their nascent interest in a particular activity into more enduring interests in a larger field of study. In their model, they hypothesized an initial phase in which interest is triggered, usually temporarily by environmental cues like surprising information or personally relevant contexts. The second phase is called maintained situational interest in which SI is sustained through meaningful tasks and/or personal involvement. In a third phase students can 
begin to form an enduring inclination toward reengaging with activities for a subject area. This emerging individual interest is characterized by stored knowledge, value, and positive affect. Finally, when individuals attain a well-developed individual interest, they exhibit positive affect, have a more robust stored knowledge and value for the subject, and are able to reengage in activities related to the subject on their own volition.

Within the four-phase model of interest development, the novelty effect is a phenomenon in which interest for a novel learning environment (e.g., our technology-related activity) is triggered. However, over time (10 days, in our case) this interest fades - SI is not maintained. Because EcoMUVE was designed to support and develop students' knowledge and skills related to scientific inquiry (see Appendix A for a detailed description), fading of triggered SI for EcoMUVE likely means that individual interest for the subject of science also suffers. However, if triggered SI for EcoMUVE is maintained, students' interest for science is more likely to benefit.

The mechanisms responsible for translating SI for an activity into individual interest for a subject are not fully understood. However, some studies provide a few possibilities. First, students' individual interest can be considered a motivational resource on which students can draw during uninteresting tasks (Katz, Assor, Kanat-Maymon, \& Bereby-Meyer, 2006; Tsai, Kunter, Lüdtke, Trautwein, \& Ryan, 2008). Therefore, more stable characteristics such as individual interest may be strong enough to surpass the effects of an uninteresting task.

Other studies, however, have suggested that features of the learning environment (rather than more stable individual differences) can trigger and maintain students' interest in an activity, and then develop into more enduring individual interest. These studies have shown that novelty (Palmer, 2009), task concreteness (Tapola, Veermans, \& Niemivirta, 2013), and stressing the 
relevance of a task (Hulleman, Godes, Hendricks, \& Harackiewicz, 2010) can develop students’

SI into more enduring individual interests. Recently, Rotgans and Schmidt (2014) suggested that learning materials are more effective at eliciting and maintaining SI when they present students with a surprising problem that highlights a gap in students' knowledge. Furthermore, from a self-determination perspective, Ryan and Deci (2000) argued that providing students with choices, building a sense of relatedness, and providing supports for their growing competence are all necessary for developing SI into more enduring forms of individual interest. In fact, Ryan and Deci argued that, "relatedness, the need to feel belongingness and connectedness with others, is centrally important for internalization" (p. 73). They also argued that, "support for autonomy allows individuals to actively transform values into their own” (p. 74). In essence, internalization (i.e., the "taking in" of a value or regulation) and integration (i.e., transforming those values and regulations into one's own sense of self) are critical in developing individuals' enduring individual interests.

\subsection{Self-Efficacy and Interest Development}

Researchers have found that interest and self-efficacy are related (Rottinghaus, Larson, \& Borgen, 2003; Silvia, 2003; Wigfield \& Eccles, 2002). In fact, Bandura (1997) has argued that interest in a domain can only develop after a firm sense of efficacy has been established first. Others argue that the relationship is not unidirectional - that they reciprocally influence each other (Boscolo \& Hidi, 2007; Del Favero, Boscolo, Vidotto, \& Vicentini, 2007; Hidi, Berndorff, \& Ainley, 2002).

The confusion surrounding the relationship between competence beliefs and interest development could center on an issue of conceptual clarity and carefully defining the task specificity of the construct. Some initial research suggests that SI may foster students' self- 
efficacy (Del Favero et al., 2007; Linnenbrink-Garcia, Patall, \& Messersmith, 2012). However, to develop an enduring form of individual interest, in which students continually re-engage with science-related activities on their own initiative, students likely need many more self-efficacy building experiences that indicate that they are indeed capable of succeeding and pursuing science-related activities. Therefore, triggered SI may spark an initial spike in self-efficacy, which may facilitate the development of a maintained SI. However, the evidence to support this hypothesis, especially by investigating longitudinal changes in self-efficacy and SI within a learning environment designed to model the kind of intellectual work that actual scientists do, is quite sparse.

Nevertheless, some initial work has shown that, within a virtual world, self-efficacy can be an important predictor of students' in-world engagement. For example, Ketelhut (2007) showed that self-efficacious students engaged in a greater quantity and diversity of scientific inquiry tasks compared to their less self-efficacious peers. Although Ketelhut did not measure interest directly, the increased engagement in scientific inquiry could suggest that students became more interested in inquiry tasks because the virtual world made the tasks meaningful and enjoyable. In fact, over time, the gap in data-collecting behaviors between high versus low selfefficacy students was nullified. In line with Hidi and Renninger's (2006) model of interest development, these results provide some preliminary evidence that MUVEs designed to engage students in inquiry tasks that simulate the intellectual work of actual scientists might help trigger an initial interest in doing the activity because it seems relevant and enjoyable. Such a virtual world also scaffolds students' inquiry skills, thereby possibly initiating an interest in both the technology activity and inquiry. Over time, this could build students' self-efficacy with the 
larger subject of science. However, the reciprocal nature of this relationship still remains an empirical question.

\section{Research Questions and Hypotheses}

Given our purposes and the theory that undergirds the present study, we were guided by the following four research questions and corresponding hypotheses:

1) To what degree does students' pre-intervention science self-efficacy predict their EcoMUVE interest profile? Given prior empirical work showing that self-efficacy for a subject is related to interest in a task (Lent et al., 2008), we hypothesize that students' science self-efficacy would predict their EcoMUVE interest profile.

2) To what degree does pre-intervention individual interest in science predict students' EcoMUVE interest profile? Empirical research has shown that students with higher individual interest in a subject tend to be more interested in activities related to that domain (Ainley, Hillman, \& Hidi, 2002; Hidi et al., 2002; Katz et al., 2006). For this reason, we hypothesized that individual interest in science would predict students' interest profile for a science-themed technology activity. However, because little research has explored whether individual interest relates to triggered SI differently than maintained SI, we do not propose any hypotheses regarding whether individual interest has a differential effect on triggered versus maintained SI.

3) To what degree does students' EcoMUVE interest profile predict post-intervention science self-efficacy, while controlling for pre-intervention self-efficacy? Theory suggests that SI fuels persistence with an activity, which could facilitate the development of self-efficacy (Hidi \& Renninger, 2006; Pajares, 1996). This claim comes with a caveat, however. Situational interest can facilitate self-efficacy development only if students are 
interested in an activity that actually helps students to develop their competence in an activity. Students can become interested in an entertaining game, but if it does little to develop their skills, it would do very little for students' science self-efficacy. As we described earlier, EcoMUVE was designed to develop students' skills in science inquiry, therefore supporting our hypothesis that students' EcoMUVE interest profile would have an effect on students' post-intervention science self-efficacy.

4) To what degree does students' EcoMUVE interest profile predict post-intervention science interest, while controlling for pre-intervention interest? Students engage in EcoMUVE over the course of 10 days and are given a significant amount of time to engage in scientific behaviors couched within an interactive, collaborative, and immersive environment. Scholars have posited that when students continually engage with a task over a significant period of time, are able to maintain a positive affect in the activity, and are able to develop their knowledge within that activity, SI can transform into a more enduring individual interest with the subject matter (Alexander, Murphy, Woods, Duhon, \& Parker, 1997; Bergin, 1999; Hidi \& Renninger, 2006; Krapp, 2005; Linnenbrink-Garcia, Patall, \& Messersmith, 2013). Because the activities that students participate in are science-focused, and because EcoMUVE was designed to provide students with a fun way to inquire scientifically through a complex problem, we hypothesized that their SI with EcoMUVE (exemplified as their interest profile) would predict their interest in science.

\section{Methods}

\subsection{Overview of EcoMUVE}


EcoMUVE is an immersive virtual world for middle school science students, which is designed to facilitate the understanding of complex causality in ecosystems. Through inquiry activities, students collaborate in this interactive environment over the course of 10 consecutive school days to explore a virtual pond ecosystem to determine the causes of a fish kill in the pond. The overall EcoMUVE curriculum involves not just the immersive virtual environment, but also time during which teachers lead discussions and tutorials about how to use various tools in the virtual world and to explore students' ideas that they generate and display in their virtual world. Time spent in the virtual world was 45 minutes per day. All teachers were instructed to introduce the activity to students in the same way. See Appendix A for a detailed description of EcoMUVE and its implementation.

\subsection{Participants}

A total of 202 Grade 6 participants were involved in the study. Participants attended a school that is set within a relatively affluent suburban area in the Northeastern United States. Two science teachers taught five classes, which on average contained 22 students per class. Grade 6 science in this school focused on life sciences, so the aquatic ecosystems unit that EcoMUVE focused on was particularly relevant for these students. Complete data were received from $94 \%$ of the students due to absences during the administration of the pre-test, the post-test, or any of the three checkpoint surveys that happened during the ten-day intervention. This allowed us to analyze data for 189 students.

\subsection{Instruments and Procedures}

Online surveys were administered for pre-, post-, and all three checkpoint assessments (see Appendix B for all items). The pre- and post-surveys, which contained a total of 40 items, assessed self-efficacy for science inquiry (e.g., "how confident are you that you can figure out 
the reasons why things happen in nature?") and individual interest in science (e.g., "I find science enjoyable"). Other variables not pertinent to this particular study were also included on these surveys. They included epistemic beliefs, science identity, and implicit theories of ability. The pre-survey was administered the day before the first day of EcoMUVE participation, and the post-survey was administered on Day 10 of EcoMUVE participation in conjunction with the last checkpoint survey. The checkpoint surveys, which were administered three times during the course of the 10 days when the students used EcoMUVE (on Days 1, 5, and 10), included four Likert scale items that assessed students' triggered SI for the technology activity (e.g., "I like using EcoMUVE"), two Likert scale items that assessed utility value (e.g., "The things I learned in the EcoMUVE activity are useful for helping me to do well in my science class"), and one Likert scale item assessing students' cost value (e.g., "It was a waste of time doing the EcoMUVE activity"). Appendix A describes the activities students participated in immediately before answering each checkpoint survey. We also included four open-ended items that asked students what they thought of EcoMUVE overall and what they learned by participating in EcoMUVE. Descriptive statistics and simple correlations between the measures are listed in Table 1. Because we wanted to ensure that the students for both teachers involved in the study did not differ appreciably, we created a dichotomous variable for teacher (TEACH) to control for teacher effects, even though both teachers used the same materials and taught using the same methods.

4.3.1. Self-efficacy for science inquiry. A number of science inquiry tasks were pertinent to participating in EcoMUVE. These tasks included collecting and analyzing data, and using those data to make causal inferences about an aquatic ecosystem. Students provided ratings on a six-point Likert scale, which indicated how confident they were in performing each 
of these tasks. Previous empirical research using confirmatory factor analysis has shown that this scale is reliable and valid (see Authors, 2014). Cronbach's alphas for this eight-item instrument were $\alpha=.88$ (pre), $\alpha=.93$ (post).

4.3.2. Individual interest in science. Because we were interested in the effect of triggered and maintained SI on students' individual interest in the field of science, we assessed students' individual interest for science class and for doing tasks in science class. This was assessed using five items from the interest/enjoyment subscale $[\alpha=.88($ pre $), \alpha=.90$ (post) $]$ of the Intrinsic Motivation Inventory (IMI; Deci, Eghrari, Patrick, \& Leone, 1994; Ryan, 1982; Ryan, Mims, \& Koestner, 1983). The scale has been shown to be a reliable and valid instrument (Koka \& Hein, 2003; McAuley, Duncan, \& Tammen, 1989). We note here that, although Hidi and Renninger (2006) posited two types of individual interest, the surveys we administered are not able to tease out the difference between emerging versus well-developed individual interest. Therefore, for the purposes of this present study, we simply claim that these items represent individual interest in science, but make no claim about whether they are emerging or welldeveloped.

4.3.3. Triggered situational interest in EcoMUVE activity. To assess students' triggered SI in the technology activity, we used four items from the interest/enjoyment section of the IMI, but asked students specifically about their interest and enjoyment for using the technology activity. Cronbach's alphas were: 0.822 (wave 1), 0.926 (wave 2), 0.958 (wave 3).

\section{Analysis}

To answer our research questions, we fit a series of latent growth models (Singer \& Willett, 2003) using the Mplus 7.11 statistical software package. We began by fitting a model of growth in students' interest in EcoMUVE, controlling for the effect of their teacher (Figure 1), 
which served as our baseline model. To answer our first research question, we then added an exogenous predictor variable, pre-intervention self-efficacy, to our baseline model (Figure 2). Similarly, to answer our second research question, we added an exogenous predictor variable, pre-intervention science interest, to the baseline model (Figure 3). These first two research questions were designed to explore relationships between individual interest in a domain and situational interests in a task (Ainley et al., 2002; Hidi et al., 2002; Katz et al., 2006) within a technologically novel environment that was designed to simulate the intellectual reasoning that an ecologist might engage in, which bolstered the authenticity of the tasks. These first two research questions also served as a way to test our control models to then use our final models to test inferences required to answer our next two research questions. We answered our third research question by using the observed and latent variables from our second model to predict post-intervention self-efficacy (Figure 4). Finally, we answered our fourth research question by using the observed and latent variables from our third model to predict post-intervention science interest (Figure 5). Our goodness-of-fit cutoffs were: fail to reject $\mathrm{H}_{0}$ in the model $\chi^{2}$ fit test, $\mathrm{RMSEA} \leq 0.08, \mathrm{CFI} \geq 0.95, \mathrm{SRMR} \leq 0.10$.

\section{Results}

We present information on the observed variables in each model, as well as model fit statistics, in Table 2. Though the RMSEA in Model 1 (0.93) was above our threshold of 0.80, all other indices exceeded our model fit criteria, and we determined that its fit was satisfactory overall. We then proceeded to add variables as outlined earlier, checking for model fit at each step. As indicated in Table 2, the fit indices for Models 2-4 met all of our criteria.

The final estimates from our fitted models are presented in Table 3. Model 1 shows that students in the class of the reference teacher had an initial interest in EcoMUVE of 5.23 ( $\mathrm{p}<.001$ ), 
with a decline in interest of $0.15(\mathrm{p}=.007)$ units with every subsequent assessment. Students in the class of the other teacher had an initial interest in EcoMUVE that was 0.45 points higher $(p<.001)$, though their rate of decay in interest matched that of their peers.

\subsection{Research Question 1: Science Self-Efficacy Predicts Interest Profile in EcoMUVE}

Table 3, Model 2 presents the results of our latent growth model in which intercept and slope for EcoMUVE interest are modeled as a function of pre-intervention science self-efficacy. Results indicate that science self-efficacy predicts triggered SI in EcoMUVE $(\beta=0.12, p=.019)$, which is modeled as the intercept value. Also, science self-efficacy predicted maintained SI in EcoMUVE $(\beta=0.11, p=.009)$, which is modeled as the rate of decline (i.e., slope) for interest in EcoMUVE. These results suggest that, for students who are less self-efficacious in science, EcoMUVE triggers their interest in EcoMUVE to a lesser degree than those who are more selfefficacious in science. Furthermore, students with lower self-efficacy evince a larger rate of decay in their EcoMUVE interest compared to their peers who are self-efficacious in science.

We highlight these trends by plotting the decay in interest of prototypical students with high (one standard deviation above sample mean) and low (one standard deviation below sample man) pre-intervention self-efficacy, controlling for teacher effects (Figure 6). At the start of EcoMUVE, high self-efficacy students reported on average an interest in the technology of 5.57, whereas the low-self efficacy students exhibited an interest value of 5.37. By the end of the intervention, however, the high self-efficacy students reported an interest of 5.39, whereas their peers with low self-efficacy reported an interest of 4.82. That is, low self-efficacy students experienced a drop in EcoMUVE interest that was more than three times greater than their high self-efficacy peers, and the gap in their EcoMUVE interest more than doubled over the course of the ten-day experience. 


\subsection{Research Question 2: Science Interest Predicts Interest Profile in EcoMUVE}

Table 3, Model 3 presents the results of our latent growth model in which intercept and slope for EcoMUVE interest are modeled as a function of pre-intervention individual interest. Results indicate that pre-intervention individual interest predicted both triggered $(\beta=0.22$, $\mathrm{p}<.0001)$ and maintained $(\beta=0.12, \mathrm{p}<.0001)$ SI for EcoMUVE. These results suggest that, compared to their peers who entered EcoMUVE with lower levels of individual interest for science, students with higher levels of individual interest experienced a more positive affective response to the technology activity during their initial experiences with EcoMUVE. These highinterest students also evinced a more gradual rate of decline in EcoMUVE interest than did their peers who had lower levels of individual interest.

We make these trends salient by plotting the decay in interest of prototypical students with high (one standard deviation above sample mean) and low (one standard deviation below sample mean) pre-intervention individual interest, controlling for teacher effects (Figure 7). At the start of EcoMUVE, students with high individual interest reported a triggered SI of 5.76, whereas students with low individual interest reported a triggered SI of 5.29. By the end of the intervention, however, the students with high individual interest still had a triggered SI of 5.68, whereas their peers with low individual interest had a triggered SI of 4.64. In summary, students with low individual interest demonstrated a drop in EcoMUVE SI that was seven times greater than that of their peers with high individual interest, and the gap between them more than doubled over time.

\subsection{Research Question 3: EcoMUVE Interest Profile Predicts Post-Intervention Science Self-Efficacy}


Table 3, Model 4 presents the results our latent growth model in which post-intervention science self-efficacy is modeled as a function of EcoMUVE interest profile. Results indicate that triggered $(\beta=0.33, \mathrm{p}=.048)$ and maintained $(\beta=0.57, \mathrm{p}=.013)$ SI in EcoMUVE predicted postintervention science self-efficacy, controlling for pre-intervention self-efficacy. This means that, controlling for pre-intervention science self-efficacy and teacher, students who evinced a stronger interest in EcoMUVE at the start of the experience, and those whose interest in EcoMUVE declined more gradually reported higher self-efficacy for science than did their peers whose initial interest in EcoMUVE was less positive and whose interest in EcoMUVE declined more rapidly.

We demonstrate this trend in Figure 8 by comparing the model estimated postintervention self efficacy of prototypical students with low (intercept and slope at the sample $20^{\text {th }}$ percentile values), median (intercept and slope at the sample $50^{\text {th }}$ percentile values), and high (intercept and slope at the sample $80^{\text {th }}$ percentile values) SI profiles, controlling for preintervention self efficacy and teacher effects by holding those variables constant at their sample mean values. Observing Figure 8, note that prototypical students with low SI had an estimated post-intervention self-efficacy value (4.31) that is nearly half a point lower than their peers who had high SI (4.80), which represents a difference of 0.52 standard deviation units.

\subsection{Research Question 4: EcoMUVE Interest Profile Predicts Post-Intervention Science Interest}

In Table 3, Model 5 we present the results of our latent growth model in which postintervention individual interest in science is modeled as a function of EcoMUVE interest profile. Results indicate that maintained $(\beta=1.11, \mathrm{p}=0.006) \mathrm{SI}$ in EcoMUVE predicted post-intervention individual interest in science, controlling for pre-intervention individual interest and teacher. 
That is, controlling for students' pre-intervention individual interest in science and teacher effects, students whose interest in EcoMUVE declined more gradually reported greater levels of individual interest in science than did their peers whose EcoMUVE interest declined more rapidly.

We highlight this trend in Figure 9 by comparing the model estimated post-intervention individual interest of prototypical students with low (intercept and slope at the sample $20^{\text {th }}$ percentile values), median (intercept and slope at the sample $50^{\text {th }}$ percentile values), and high (intercept and slope at the sample $80^{\text {th }}$ percentile values) SI profiles, controlling for preintervention individual interest and teacher effects. Observing Figure 9, note that prototypical students with low SI had an estimated post-intervention individual interest value (4.34) that is over half a point lower than their peers who have high SI (4.94), which represents a difference of 0.54 standard deviations.

\section{Discussion}

\subsection{Self-Efficacy and Situational Interest}

7.1.1. Science self-efficacy predicted interest with EcoMUVE. Our results contribute to a small but growing empirical literature showing a reciprocal relationship between self-efficacy and interest. The present study clarifies this relationship by showing that students' preintervention self-efficacy for science had an effect both on students' triggered situational interest (SI) for EcoMUVE (i.e., the initial level of EcoMUVE interest) and on students' maintained SI for EcoMUVE (i.e., the rate of decay for EcoMUVE interest). Although some empirical literature has shown that perceived competence in an academic field can influence a student's SI in that field, our results show that self-efficacy for science has an effect on students' initial enjoyment with a MUVE, and for how quickly or slowly their interest for the technology wanes. 
This suggests that technology-rich activities are not always an effective way to motivate students. That is, even though EcoMUVE was designed to be enjoyable and interesting, students' pre-existing self-efficacy for science still had a measurable impact on how interested students were in our MUVE, and how well that interest was sustained. Students with low self-efficacy, on average, had a lower (though, still high) amount of initial interest with EcoMUVE, and lost interest in EcoMUVE more quickly than did their peers with higher self-efficacy. Future research should investigate ways that can help less self-efficacious students to remain interested in rich science inquiry content. The work of Authors (2014) showed that students who believed that their intellectual capacities in science could grow (Dweck \& Leggett, 1988; incremental view of ability) and who identified strongly with scientists evinced gains in science interest, whereas their peers who believed that intellectual capacities are fixed at birth (fixed view of ability) and who did not identify with scientists showed no growth in science interest. Therefore, one possible pathway for further investigation could be to explore ways to help students identify more strongly with the work of scientists and to facilitate the belief that abilities and skills in science can be amplified through appropriate strategy use and effortful practice.

7.1.2. Situational interest in EcoMUVE predicted science self-efficacy. The present study also contributes to theory regarding the reciprocal nature of interest development and selfefficacy by illustrating the importance of triggering and maintaining SI. Linnenbrink-Garcia et al. (2012) found triggered SI had an effect on perceived competence, but neither maintained SI (feeling) nor maintained SI (value) did. Our results, however, modify and clarify the relationship between SI and self-efficacy by illustrating that both triggering and maintaining SI in EcoMUVE were important in developing students' science self-efficacy. In fact, maintaining SI in EcoMUVE had an effect that was over 1.5 times larger on post-intervention science self-efficacy 
than did triggering SI, emphasizing the importance of curricular materials that sustain students' interests.

What may have contributed to this discrepancy? Linnenbrink-Garica et al. (2012) assessed maintained SI (feeling) by asking students how enjoyable they thought their class was. They also assessed maintained SI (value) by asking students how valuable they thought the course material was. For the present study, our measure for maintained SI was created using a latent growth model illustrating the decay of EcoMUVE interest that occurred over the 10-day instructional period. We posit that this model of interest decay for the technology reveals insights about how the maintenance of students' interests in curricular materials is critically important to the development of students' self-efficacy. In fact, students whose interest in EcoMUVE decayed at a slower rate reported their self-efficacy in science to be 0.6 standard deviations higher than their peers with a rate of decay that was one unit faster in decline.

What might be a mechanism through which triggered and maintained SI facilitated the development of self-efficacy? Bandura (1997) posited that self-efficacy is influenced through four sources. For the purposes of our study, we discuss only one source, which we believe was salient for students participating in EcoMUVE_-individuals' emotions and other physiological and affective states. Positive emotions like happiness and excitement can build self-efficacy whereas negative emotions such as anxiety and frustration can diminish it. With EcoMUVE, it is plausible that students experienced positive emotions while interacting in EcoMUVE. These positive affective states may have facilitated the development of students' self-efficacy. In fact SI can be considered a type of affective state, as Krapp, Hidi, and Renninger (1992) noted. This could be similar to what Linnenbrink-Garcia et al. (2012) called maintained SI (feeling). If so, it 
may be more advantageous to assess changes in affect and how those changes relate to students' self-efficacy and interest, rather than simply the level of affect.

\subsubsection{Triggered and maintained EcoMUVE interest predicted interest in science.}

EcoMUVE appeared to do a reasonably good job of translating students' maintained SI for a technology activity into an individual interest in science. Linnenbrink-Garcia et al. (2012)

posited that students experiencing maintained SI demonstrate positive feelings toward the actual academic content. We expand on this model of interest development by showing that this triggered SI for the technology translated into individual interest for the science content, but only if that triggered SI in EcoMUVE was maintained.

Also, because we were able to decompose interest in EcoMUVE into both triggered and maintained SI, we were able to show that triggered SI in EcoMUVE was not an important contributor to students' post-intervention individual interest in science. Rather, it was maintained SI in EcoMUVE that had a statistically significant effect on students' individual interest. This suggests that designing rich inquiry environments that maintain students' SI in a technology activity that helps build meaningful skills can be successful in facilitating the transition to more enduring forms of individual interest. However, as we saw with students who lost interest in EcoMUVE at a faster rate, technology activities that only trigger SI but do not sustain it are likely to do little in the way of facilitating the development of interest in an academic subject.

\section{Limitations}

We acknowledge that there were limitations to our study. First, our study only involved two teachers' classes, which were set within a suburban school context in the Northeastern United States. Therefore, generalizations outside of this context should be done with great 
caution. Furthermore, although the results from these two teachers' students does provide us with some preliminary evidence regarding teachers' effects in interest development, a larger and more varied sample of teachers should be used to verify our findings.

Second, we note that, although we could have modeled science interest and self-efficacy simultaneously rather than separately in different models, we conducted separate analyses due to sample size limitations. We were just at the "limit" for number of observations to fit a structural equation model, which Kline (2011) recommended to be $\mathrm{n}=200$. The model complexity and loss of degrees of freedom limited our ability to properly fit and make inferences from this larger model. Therefore, in future scholarship, researchers could use larger sample sizes to test moderation effects with interest and self-efficacy.

Next, although we collected data regarding the utility of EcoMUVE during our three checkpoint surveys (i.e., maintained SI-value), we could not use these data. We attempted to model the change in students' maintained SI (value) using these items. However, none of the model fit indicators was good. The reason for the poor fit came down to the fact that maintained SI (value) followed a quadratic trend over time - it rose and then fell on average. When trying to fit the utility data with a quadratic specification, the model failed to converge and resulted in negative degrees of freedom, suggesting we would need at least one more wave of data.

Also, although knowledge outcomes were not modeled in this study, past studies involving EcoMUVE have shown knowledge gains from pre- to post-intervention (Authors, 2013). In the future, researchers could investigate both motivational dynamics and knowledge outcomes modeled simultaneously. Furthermore, because students worked collaboratively in EcoMUVE, generalizing these findings to contexts in which students participate in technology- 
rich contexts individually should be done with great caution because collaboration might play an important role in developing situational and individual interest (Hidi \& Renninger, 2012).

Finally, although we discuss the effects on students' individual interest and self-efficacy of the triggered and maintained SI that was generated by participation in EcoMUVE, we are discussing them in the statistical sense such that we describe relationships as effect sizes rather than in the causal sense. To provide better evidence of causality, researchers could include experimental studies that manipulate triggered SI and/or maintained SI for technology. Researchers could also collect more detailed data (e.g., log file data about user interactions) about how students use the technology. Collecting this kind of detailed moment-to-moment data to complement survey data would be welcome in examining how different features of such virtual worlds can have an impact on students' motivation.

\section{Conclusions}

These limitations notwithstanding, our study contributes to the literature by showing how situational interest that was triggered and maintained through participation in EcoMUVE was related to the development of students' individual interests in the field of science as well as students' science self-efficacy. The real value of EcoMUVE was that, with continued use in the activity (over the course of 10 school days), and despite the overall decline in students' situational interest with EcoMUVE (i.e., a novelty effect), there was a corresponding increase in students' interest in the field of science for those whose SI dropped gradually rather than steeply. Where so many activities, technology-rich or otherwise, have failed is in translating excitement with a classroom activity into more enduring interests with a larger field of study. Because we were able to separately analyze the intercept (triggered SI for EcoMUVE) and slope (maintained SI for EcoMUVE) of our models, we were able to provide empirical evidence that technology- 
rich activities that spark an interest in an activity, but then sustain students' interests in the actual tasks of scientific inquiry may encourage students to turn their attention from the technology-rich activity to the field of science. 


\section{REFERENCES}

Authors (2013)

Authors (2014)

Adams, D. M., Mayer, R. E., MacNamara, A., Koenig, A., \& Wainess, R. (2012). Narrative games for learning: Testing the discovery and narrative hypotheses. Journal of Educational Psychology, 104(1), 235-249. http://doi.org/10.1037/a0025595

Ainley, M., Hillman, K., \& Hidi, S. (2002). Gender and interest processes in response to literary texts: Situational and individual interest. Learning and Instruction, 12(4), 411-428.

Alexander, P. A., Murphy, P. K., Woods, B. S., Duhon, K. E., \& Parker, D. (1997). College instruction and concomitant changes in students' knowledge, interest, and strategy use: A study of domain learning. Contemporary Educational Psychology, 22(2), 125-146. http://doi.org/10.1006/ceps.1997.0927

Bandura, A. (1997). Self-efficacy: The exercise of control. New York, NY: Freeman.

Barab, S. A., Gresalfi, M., \& Ingram-Goble, A. (2010). Transformational play: Using games to position person, content, and context. Educational Researcher, 39(7), 525-536. http://doi.org/10.3102/0013189X10386593

Bergin, D. A. (1999). Influences on classroom interest. Educational Psychologist, 34(2), 87-98.

Boscolo, P., \& Hidi, S. (2007). The multiple meanings of motivation to write. Writing and Motivation, 19, 1.

Chen, J. A., Metcalf, S. J., \& Tutwiler, M. S. (2014). Motivation and beliefs about the nature of scientific knowledge within an immersive virtual ecosystems environment. Contemporary Educational Psychology, 39(2), 112-123. http://doi.org/10.1016/j.cedpsych.2014.02.004 
Chen, J. A., Zap, N., \& Dede, C. (2012). Using virtual environments to motivate students to pursue STEM careers: An expectancy-value model. In S. D’Agustino (Ed.), Immersive Environments, Augmented Realities, and Virtual Worlds: Assessing Future Trends in Education (pp. 42-56). Hershey, PA: IGI Global.

Clark, R. E. (1983). Reconsidering research on learning from media. Review of Educational Research, 53(4), 445-459.

Dalgarno, B., \& Lee, M. J. W. (2010). What are the learning affordances of 3-D virtual environments? British Journal of Educational Technology, 41(1), 10-32. http://doi.org/10.1111/j.1467-8535.2009.01038.x

Deaney, R., Ruthven, K., \& Hennessy, S. (2003). Pupil perspectives on the contribution of information and communication technology to teaching and learning in the secondary school. Research Papers in Education, 18(2), 141-165.

Deci, E. L., Eghrari, H., Patrick, B. C., \& Leone, D. R. (1994). Facilitating internalization: The self-determination theory perspective. Journal of Personality, 62(1), 119-142.

Dede, C. (2009). Immersive interfaces for engagement and learning. Science, 323(5910), 66-69. http://doi.org/10.1126/science.1167311

Del Favero, L., Boscolo, P., Vidotto, G., \& Vicentini, M. (2007). Classroom discussion and individual problem-solving in the teaching of history: Do different instructional approaches affect interest in different ways? Learning and Instruction, 17(6), 635-657. http://doi.org/10.1016/j.learninstruc.2007.09.012

Dweck, C. S., \& Leggett, E. L. (1988). A social-cognitive approach to motivation and personality. Psychological Review, 95(2), 256. 
Hidi, S., Berndorff, D., \& Ainley, M. (2002). Children's argument writing, interest and selfefficacy: an intervention study. Learning and Instruction, 12(4), 429-446. http://doi.org/10.1016/S0959-4752(01)00009-3

Hidi, S., \& Renninger, K. A. (2006). The four-phase model of interest development. Educational Psychologist, 41(2), 111-127.

Hulleman, C. S., Godes, O., Hendricks, B. L., \& Harackiewicz, J. M. (2010). Enhancing interest and performance with a utility value intervention. Journal of Educational Psychology, 102(4), 880-895. http://doi.org/10.1037/a0019506

Hulleman, C. S., \& Harackiewicz, J. M. (2009). Promoting interest and performance in high school science classes. Science, 326(5958), 1410-1412. http://doi.org/10.1126/science.1177067

Katz, I., Assor, A., Kanat-Maymon, Y., \& Bereby-Meyer, Y. (2006). Interest as a motivational resource: Feedback and gender matter, but interest makes the difference. Social Psychology of Education, 9(1), 27-42.

Ketelhut, D. J. (2007). The impact of student self-efficacy on scientific inquiry skills: An exploratory investigation in River City, a multi-user virtual environment. Journal of Science Education and Technology, 16(1), 99-111. http://doi.org/10.1007/s10956-0069038-y

Koka, A., \& Hein, V. (2003). Perceptions of teacher's feedback and learning environment as predictors of intrinsic motivation in physical education. Psychology of Sport and Exercise, 4(4), 333-346. 
Krapp, A. (2005). Basic needs and the development of interest and intrinsic motivational orientations. Learning and Instruction, 15(5), 381-395. http://doi.org/10.1016/j.learninstruc.2005.07.007

Lent, R. W., Sheu, H.-B., Singley, D., Schmidt, J. A., Schmidt, L. C., \& Gloster, C. S. (2008). Longitudinal relations of self-efficacy to outcome expectations, interests, and major choice goals in engineering students. Journal of Vocational Behavior, 73(2), 328-335. http://doi.org/10.1016/j.jvb.2008.07.005

Linnenbrink-Garcia, L., Patall, E. A., \& Messersmith, E. E. (2013). Antecedents and consequences of situational interest. British Journal of Educational Psychology, 83(4), 591-614. http://doi.org/10.1111/j.2044-8279.2012.02080.x

McAuley, E., Duncan, T., \& Tammen, V. V. (1989). Psychometric properties of the Intrinsic Motivation Inventory in a competitive sport setting: A confirmatory factor analysis. Research Quarterly for Exercise and Sport, 60(1), 48-58.

Moos, D. C., \& Marroquin, E. (2010). Multimedia, hypermedia, and hypertext: Motivation considered and reconsidered. Computers in Human Behavior, 26(3), 265-276. http://doi.org/10.1016/j.chb.2009.11.004

Moreno, R., \& Mayer, R. E. (2004). Personalized messages that promote science learning in virtual environments. Journal of Educational Psychology, 96(1), 165-173. http://doi.org/10.1037/0022-0663.96.1.165

Muthén, L. K., \& Muthén, B. O. (1998). Mplus User’s Guide. Seventh Edition (Version 7.11). Los Angeles, CA.

Pajares, F. (1996). Self-efficacy beliefs in academic settings. Review of Educational Research, 66(4), 543-578. 
Palmer, D. H. (2009). Student interest generated during an inquiry skills lesson. Journal of Research in Science Teaching, 46(2), 147-165.

Rotgans, J. I., \& Schmidt, H. G. (2014). Situational interest and learning: Thirst for knowledge. Learning and Instruction, 32, 37-50.

Rottinghaus, P. J., Larson, L. M., \& Borgen, F. H. (2003). The relation of self-efficacy and interests: a meta-analysis of 60 samples. Journal of Vocational Behavior, 62(2), 221-236.

Ryan, R. M. (1982). Control and information in the intrapersonal sphere: An extension of cognitive evaluation theory. Journal of Personality and Social Psychology, 43(3), 450.

Ryan, R. M., \& Deci, E. L. (2000). Self-determination theory and the facilitation of intrinsic motivation, social development, and well-being. American Psychologist, 55(1), 68.

Ryan, R. M., Mims, V., \& Koestner, R. (1983). Relation of reward contingency and interpersonal context to intrinsic motivation: A review and test using cognitive evaluation theory. Journal of Personality and Social Psychology, 45(4), 736.

Silvia, P. J. (2003). Self-efficacy and interest: Experimental studies of optimal incompetence. Journal of Vocational Behavior, 62(2), 237-249. http://doi.org/10.1016/S00018791(02)00013-1

Singer, J. D., \& Willett, J. B. (2003). Applied longitudinal data analysis: Modeling change and event occurrence. New York, NY: Oxford University Press.

Tapola, A., Veermans, M., \& Niemivirta, M. (2013). Predictors and outcomes of situational interest during a science learning task. Instructional Science, 41(6), 1047-1064. http://doi.org/10.1007/s11251-013-9273-6 
Torff, B., \& Tirotta, R. (2010). Interactive whiteboards produce small gains in elementary students' self-reported motivation in mathematics. Computers \& Education, 54(2), 379383. http://doi.org/10.1016/j.compedu.2009.08.019

Tsai, Y.-M., Kunter, M., Lüdtke, O., Trautwein, U., \& Ryan, R. M. (2008). What makes lessons interesting? The role of situational and individual factors in three school subjects. Journal of Educational Psychology, 100(2), 460.

Wigfield, A., \& Eccles, J. S. (2002). The development of competence beliefs, expectancies for success, and achievement values from childhood through adolescence. In A. Wigfield \& J. S. Eccles (Eds.), Development of Achievement Motivation (pp. 91-120). San Diego, CA: Academic Press. 
Acknowledgements -- must be submitted separately from the manuscript

\section{Acknowledgements}

EcoMUVE was supported by the Institute of Education Sciences, U.S. Department of Education, Grant No. R305A080514 to Chris Dede and Tina Grotzer. All opinions, findings, conclusions or recommendations expressed here are those of the authors and do not necessarily reflect the views of the Institute for Education Sciences. 
Table1. Descriptive statistics and simple Pearson correlations

\begin{tabular}{|c|c|c|c|c|c|c|c|c|c|c|c|c|}
\hline & & $\mathrm{N}$ & Mean & $\mathrm{sd}$ & 1 & 2 & 3 & 4 & 5 & 6 & 7 & 8 \\
\hline 1 & Pre SE & 189 & 4.24 & 0.85 & 1 & & & & & & & \\
\hline 2 & Pre INT & 188 & 4.62 & 1.08 & $.43 * * *$ & 1 & & & & & & \\
\hline 3 & TEACH & 189 & 0.53 & 0.50 & -.03 & $.18 *$ & 1 & & & & & \\
\hline 4 & SIT1 & 182 & 5.49 & 0.65 & $.16^{*}$ & $.41 * * *$ & $.36 * * *$ & 1 & & & & \\
\hline 5 & SIT2 & 189 & 5.28 & 0.93 & $.18 *$ & $.41 * * *$ & $.14^{*}$ & $.65 * * *$ & 1 & & & \\
\hline 6 & SIT3 & 189 & 5.12 & 1.30 & $.23 * *$ & $.41 * * *$ & $.15^{*}$ & $.61 * * *$ & $.77 * * *$ & 1 & & \\
\hline 7 & Post SE & 189 & 4.44 & 0.95 & $.57 * * *$ & $.37 * * *$ & .09 & $.34 * * *$ & $.39 * * *$ & $.46^{* * * *}$ & 1 & \\
\hline 8 & Post INT & 189 & 4.61 & 1.11 & $.36 * * *$ & $.81 * * *$ & $.21 * *$ & $.49 * * *$ & $.57 * * *$ & $.63 * * *$ & $.56 * * *$ & 1 \\
\hline
\end{tabular}

$\mathrm{p}<.05, * * \mathrm{p}<.01, * * * \mathrm{p}<.001$ 
Table 2. Model fit statistics

\begin{tabular}{lccccccc} 
Model (Variables) & n_free parameters & $\chi^{2}$ & df & value & RMSEA & CFI & SRMR \\
\hline M1 (Teacher) & 10 & 5.298 & 2 & 0.0707 & 0.093 & 0.989 & 0.036 \\
M2 (M1+Pre Self-Efficacy) & 12 & 6.062 & 3 & 0.1086 & 0.073 & 0.990 & 0.037 \\
M3 (M1+Pre Science Interest) & 12 & 5.155 & 3 & 0.1608 & 0.062 & 0.994 & 0.032 \\
M4 (M2+Post Self-Efficacy) & 18 & 6.631 & 4 & 0.1567 & 0.059 & 0.994 & 0.041 \\
M5 (M3+Post Science Interest) & 18 & 5.448 & 4 & 0.2443 & 0.044 & 0.998 & 0.034 \\
\hline
\end{tabular}


Table 3. Taxonomy of situated interest growth models

\begin{tabular}{|c|c|c|c|c|c|}
\hline Parameters & Model 1 & Model 2 & Model 3 & Model 4 & Model 5 \\
\hline \multicolumn{6}{|l|}{ Means } \\
\hline Intercept & $5.23 * * *$ & $5.23 * * *$ & $5.28 * * *$ & $5.23 * * *$ & $5.28 * * *$ \\
\hline Slope & $0.15^{* *}$ & $0.15 * *$ & $0.12 * *$ & $0.15^{* *}$ & $0.12 *$ \\
\hline Post SelfEfficacy & & & & $2.71 * *$ & \\
\hline Post Science Interest & & & & & $4.48 * *$ \\
\hline \multicolumn{6}{|l|}{ Effects } \\
\hline Teacher $\rightarrow$ Intercept & $0.45 * * *$ & $0.46^{* * *}$ & $0.36 * * *$ & $0.46 * * *$ & $0.37 * * *$ \\
\hline Teacher $\rightarrow$ Slope & 0.06 & 0.06 & 0.11 & 0.05 & 0.11 \\
\hline Teacher $\rightarrow$ Post SelfEfficacy & & & & 0.08 & \\
\hline Teacher $\rightarrow$ Post Science Interest & & & & & 0.24 \\
\hline Pre SelfEfficacy ${ }^{\mathrm{a}} \rightarrow$ Intercept & & $0.12 *$ & & $0.12 *$ & \\
\hline Pre SelfEfficacy $^{\mathrm{a}} \rightarrow$ Slope & & $0.11 * *$ & & $0.11 * *$ & \\
\hline Pre SelfEfficacy $^{\mathrm{a}} \rightarrow$ Post SelfEfficacy & & & & $0.53 * * *$ & \\
\hline Pre Science Interest ${ }^{\mathrm{a}} \rightarrow$ Intercept & & & $0.22 * * *$ & & $0.22 * * *$ \\
\hline Pre Science Interest $^{\mathrm{a}} \rightarrow$ Slope & & & $0.13 * * *$ & & $0.13 * * *$ \\
\hline Pre Science Interest ${ }^{\mathrm{a}} \rightarrow$ Post Science Interest & & & & & $0.68 * * *$ \\
\hline Intercept $\rightarrow$ Post SelfEfficacy & & & & $0.33 *$ & \\
\hline Intercept $\rightarrow$ Post Science Interest & & & & & 0.04 \\
\hline Slope $\rightarrow$ Post Self Efficacy & & & & $0.57 *$ & \\
\hline Slope $\rightarrow$ Post Science Interest & & & & & $1.11 * *$ \\
\hline \multicolumn{6}{|l|}{ Variances } \\
\hline Intercept & $0.25 * * *$ & $0.25 * * *$ & $0.20 * * *$ & $0.26 * * *$ & $0.29 * * *$ \\
\hline Slope & $0.15 * * *$ & $0.15 * * *$ & $0.14 * *$ & $0.16 * * *$ & $0.18 * * *$ \\
\hline \multicolumn{6}{|l|}{ Covariances } \\
\hline Intercept-Slope & $0.11 * * *$ & $0.10 * *$ & $0.08 *$ & $0.09 * *$ & $0.08 *$ \\
\hline
\end{tabular}

Note: Cell entries are model estimates 
${ }^{a}$ Grandmean centered $* \mathrm{p}<.05, * * \mathrm{p}<.01, * * * \mathrm{p}<.001$ 


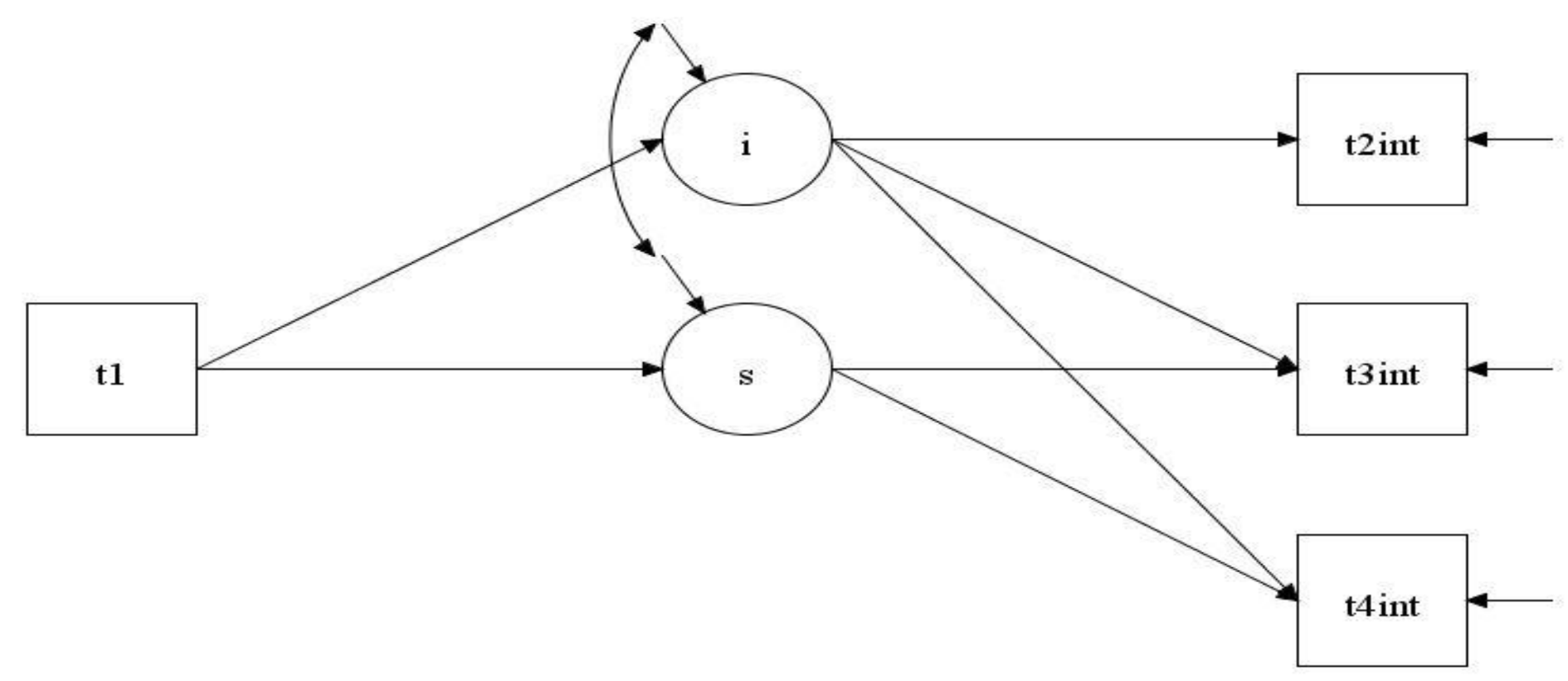

Figure 1. Triggered and Maintained Situational Interest in EcoMUVE, Controlling for Teacher (Model 1) 


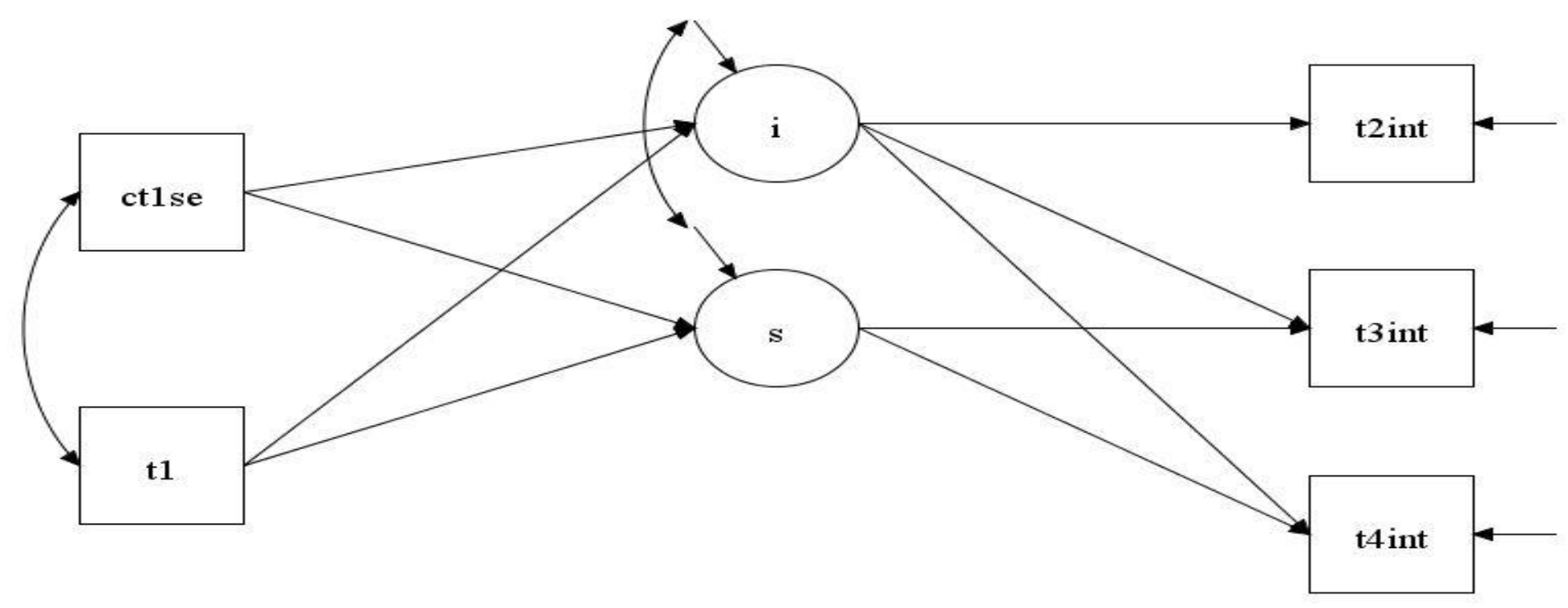

Figure 2. Effect of Pre-Intervention Science Self-Efficacy, Centered on Sample Mean (ct1se), on Triggered and Maintained Situational Interest in EcoMUVE, Controlling for Teacher (Model 2) 


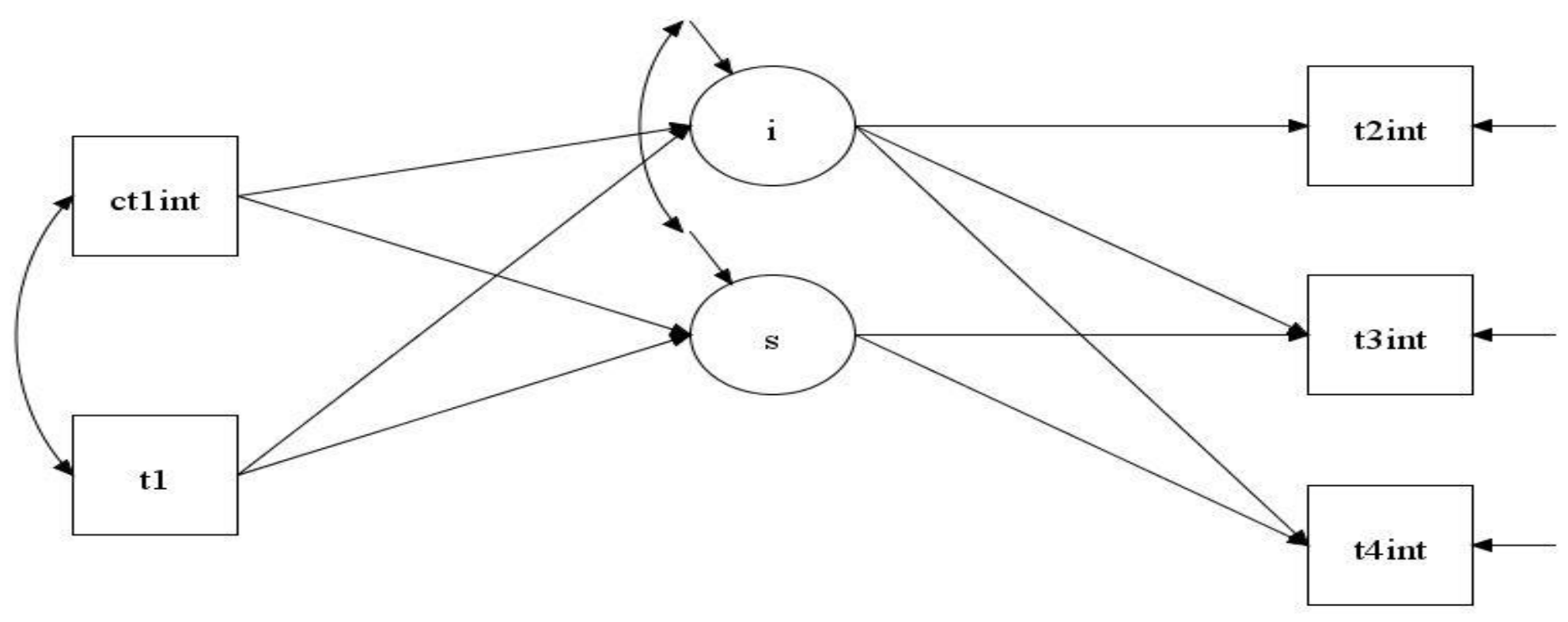

Figure 3. Effect of Pre-Intervention Science Interest, Centered on Sample Mean (t1int), on Triggered and Maintained Situational Interest in EcoMUVE, Controlling for Teacher (Model 3) 


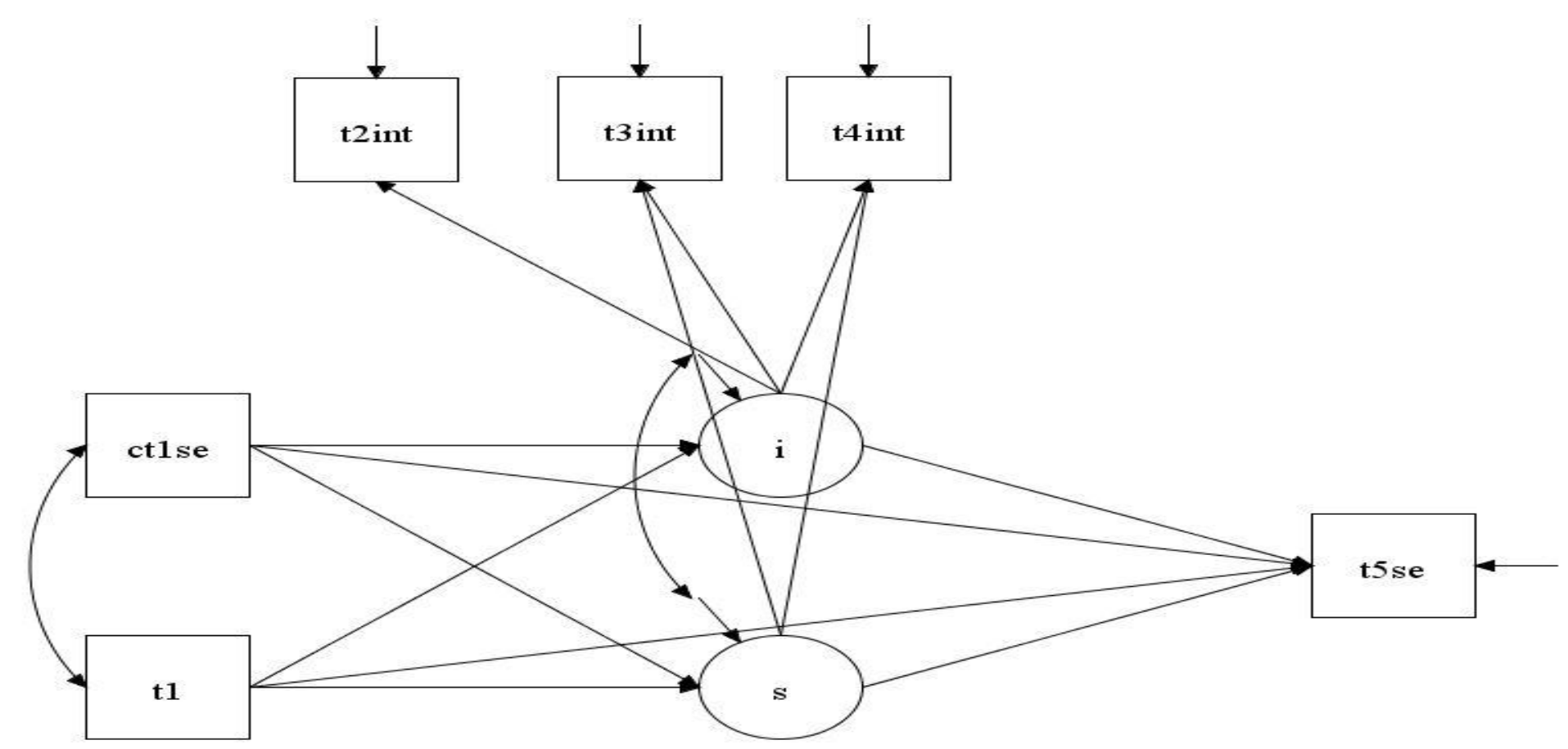

Figure 4. Effects of Triggered and Maintained Situational Interest in EcoMUVE on Post-Intervention Science Self-Efficacy, Controlling for Centered Pre-Intervention Science Self-Efficacy and Teacher (Model 4) 


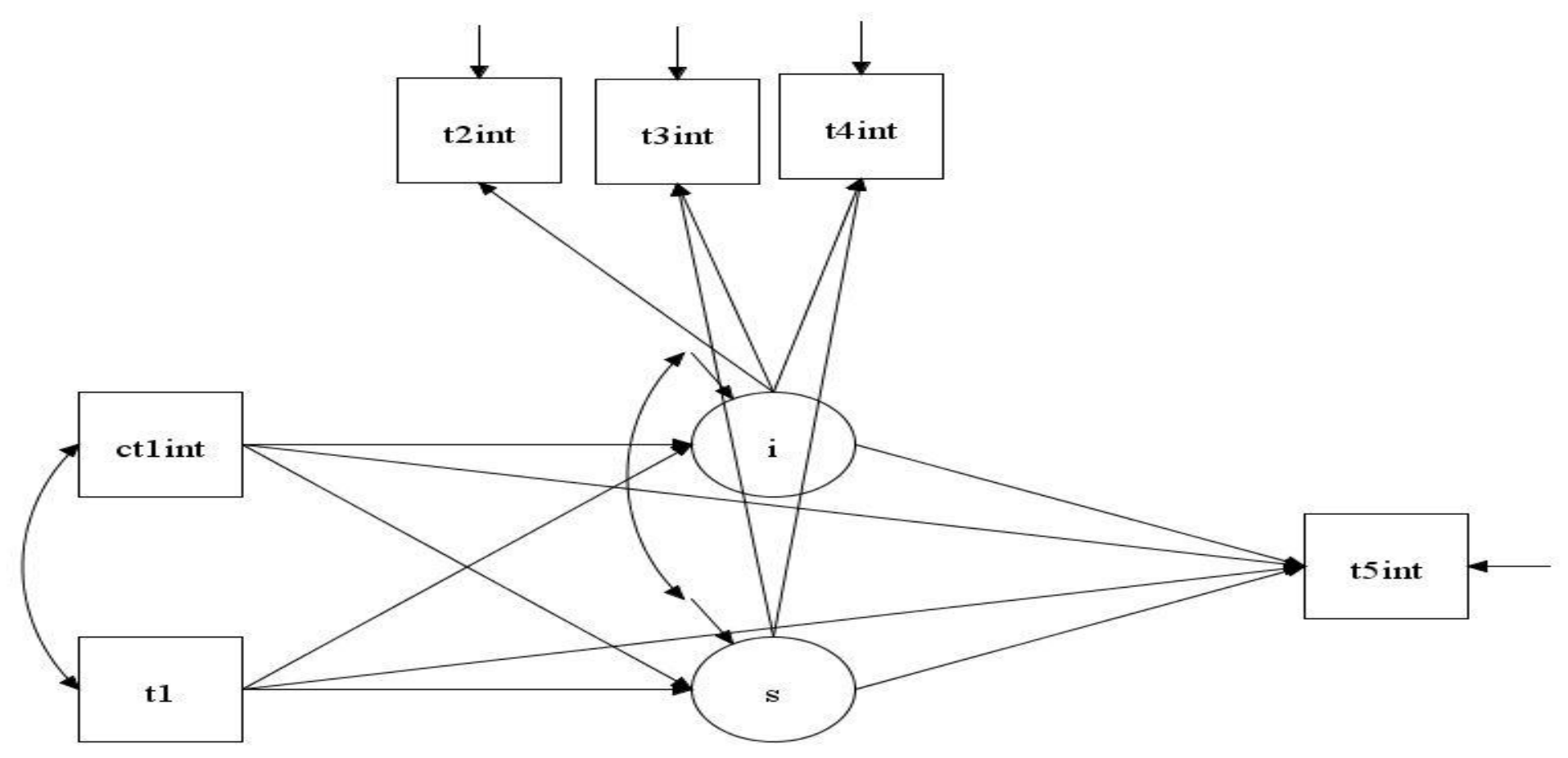

Figure 5. Effects of Triggered and Maintained Situational Interest in EcoMUVE on Post-Intervention Science Interest, Controlling for Centered Pre-Intervention Science Interest and Teacher (Model 5) 


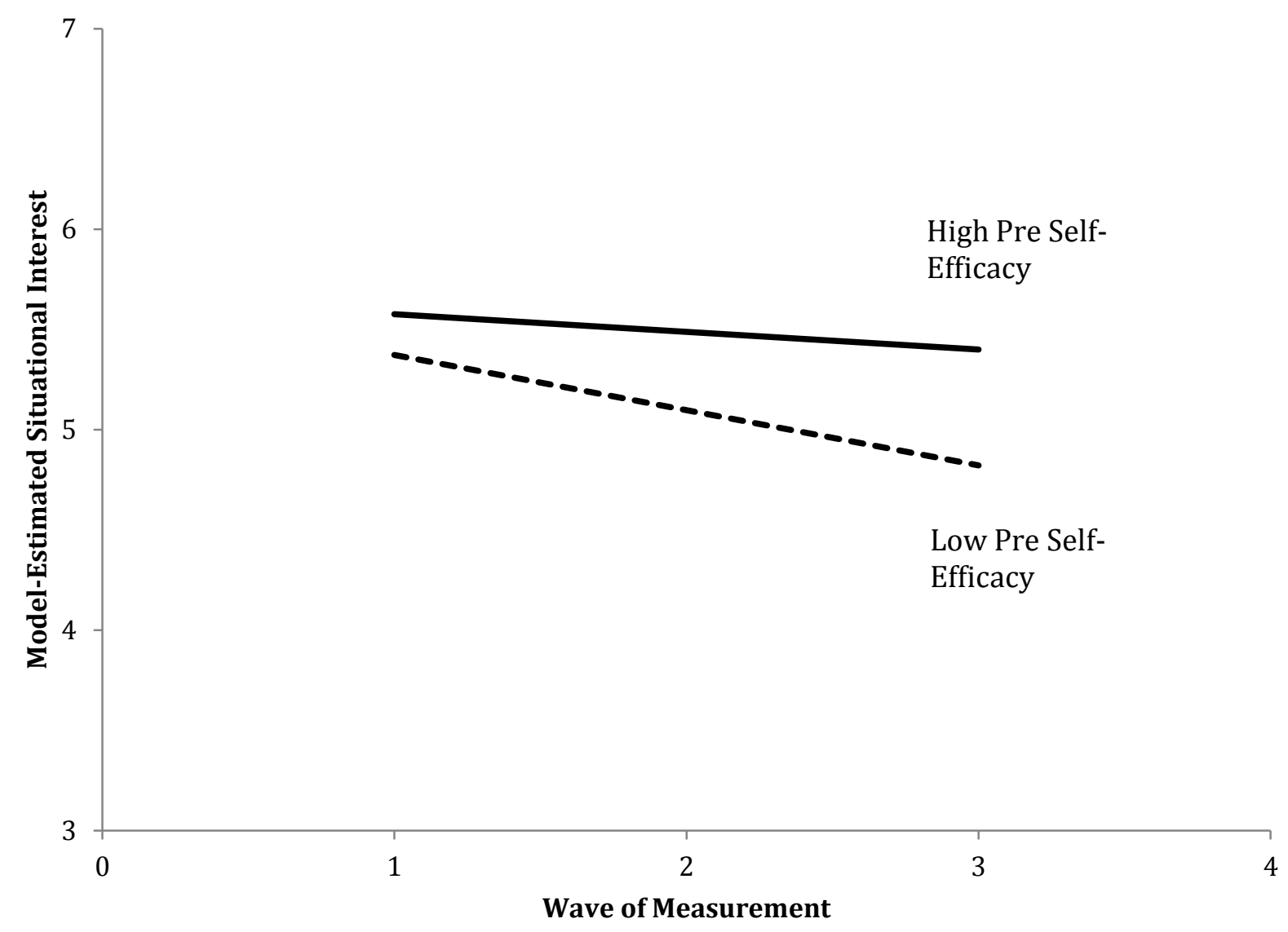

Figure 6. Model Estimated Latent Growth in Interest in EcoMUVE of Prototypical $6^{\text {th }}$ Grade Students (Model 2). 


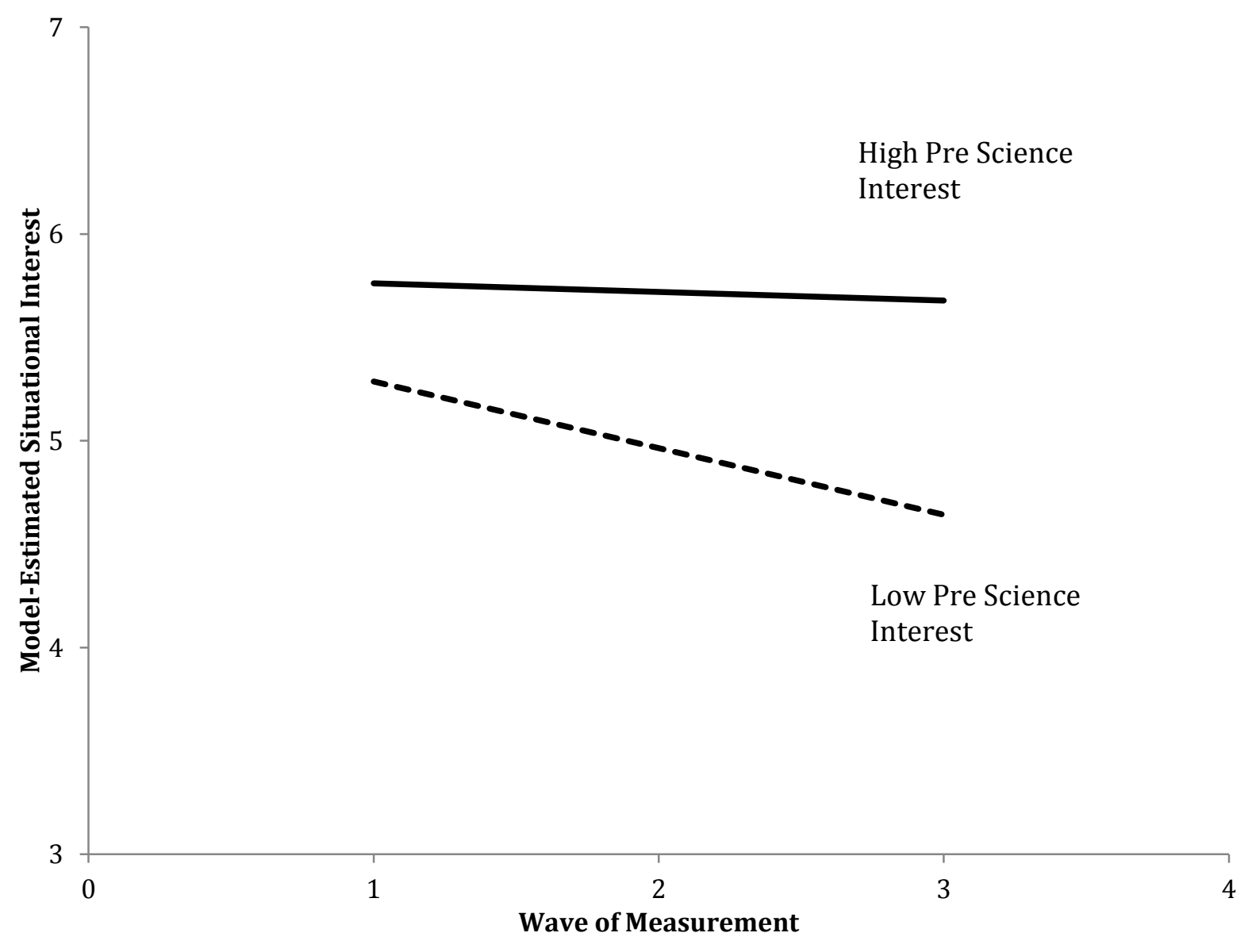

Figure 7. Model Estimated Latent Growth in Interest in EcoMUVE of Prototypical $6^{\text {th }}$ Grade Students (Model 3). 


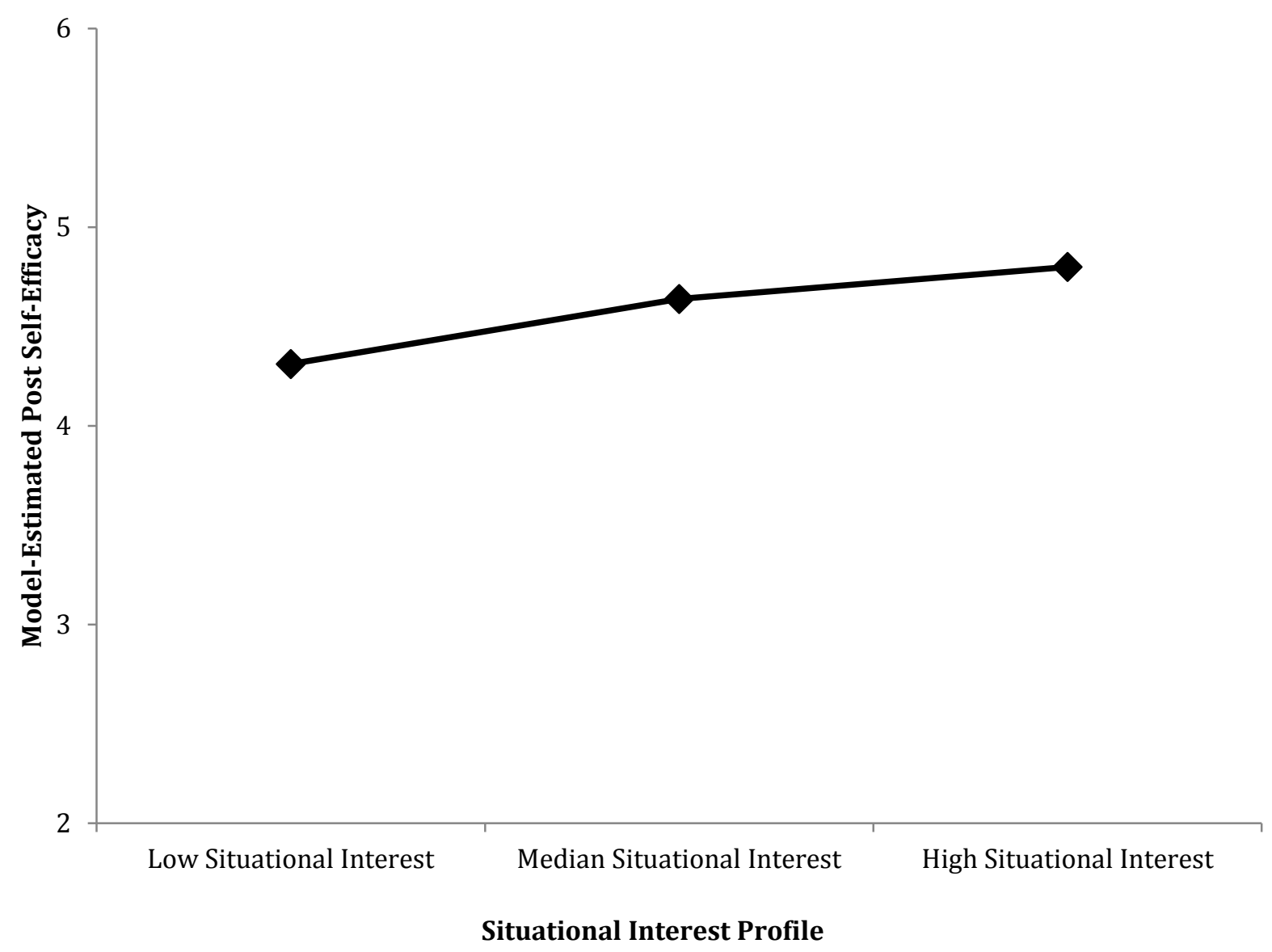

Figure 8. Model Estimated Post-Intervention Self-Efficacy of Prototypical $6^{\text {th }}$ Grade Students (Model4). 


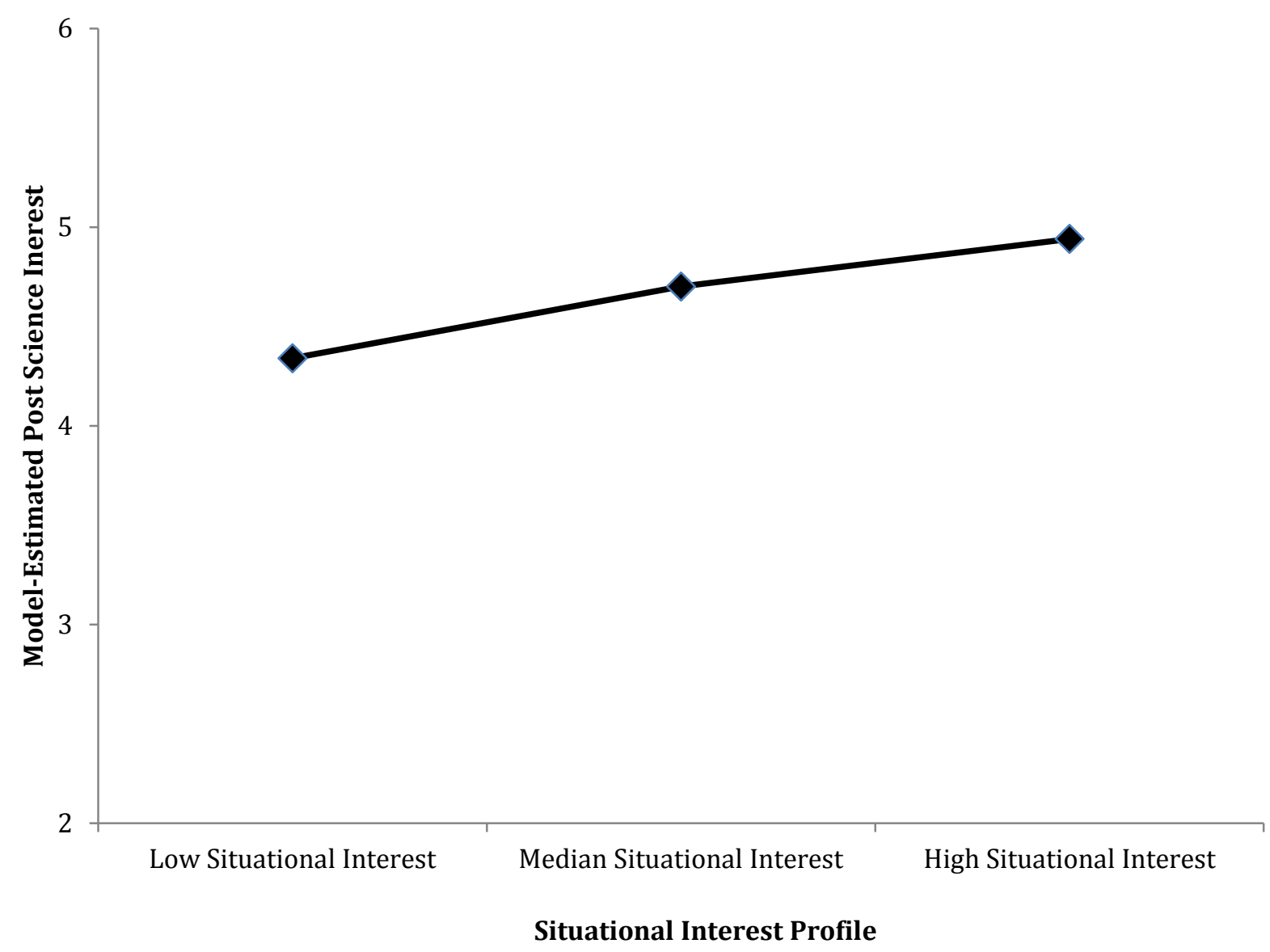

Figure 9. Model Estimated Post-Intervention Science Interest of Prototypical $6^{\text {th }}$ Grade Students (Model5). 